\title{
Short communication: Survey of fresh cow management practices of dairy cattle on small and large commercial farms
}

\author{
W. Heuwieser, ${ }^{* 1,2}$ M. Iwersen, ${ }^{*}$ J. Gossellin, $\dagger$ and M. Drillich* \\ ${ }^{*}$ Clinic for Animal Reproduction, Faculty of Veterinary Medicine, Freie Universität Berlin, Königsweg 65, 14163 Berlin, Germany \\ †Pfizer Animal Health, Veterinary Medicine Research and Development, Ramsgate Road, Sandwich, Kent CT13 9NJ, United Kingdom
}

\begin{abstract}
The objective was to conduct a survey of current fresh cow management practices that have an effect on health and diseases postpartum considering different herd sizes of commercial dairy farms. A mail survey regarding aspects of the fresh cow program including general management issues, calving, diseases, and veterinary service was conducted utilizing a convenience sample. A total of 429 survey forms were returned (12.0\% response rate) and could be used for final analysis. Only $21.6 \%$ of the farms had a designated fresh cow pen. Almost every farm executed some type of fresh cow examination. Only $18.5 \%$ of farm managers documented the observations. Most of the dairy managers used more or less subjective criteria such as general appearance (97.0\%) and appetite (69.7\%). Only a minority of the responding dairy managers monitored their fresh cows using objective (fever 33.6\%) or semiquantitative measures (subclinical ketosis 2.8\%; body condition score $36.4 \%$ ). On most farms, the veterinarian visited the herd only if needed (72.6\%). Most cases of retained fetal membranes were treated by manual removal $(72.3 \%)$ and antibiotic pills (89.5\%). Several challenges and opportunities were identified to improve cow management practices.
\end{abstract}

Key words: fresh cow, postpartum, reproduction, herd management survey

Recently, surveys have provided important insights into current dairy management practices and experiences in a variety of areas such as reproductive performance, high milk production, colostrum management, crossbreeding, and antibiotic usage (Caraviello et al., 2006; Kehoe et al., 2007; Fulwider et al., 2008).

Intensive research has focused on the postpartum period of dairy cows. Particularly, risk factors for disease and their relationships to production and reproductive

Received October 1, 2009

Accepted December 3, 2009.

${ }^{1}$ Current address: Animal Welfare Program, Faculty of Land and Food Systems, The University of British Columbia, 2357 Main Mall, Vancouver, BC, V6T 1Z4, Canada.

${ }^{2}$ Corresponding author: wolfgang.heuwieser@ubc.ca performance as well as intervention strategies for common disorders such as retained fetal membranes and acute postpartum metritis were intensively studied and recently reviewed (LeBlanc et al., 2006; Azawi, 2008). Despite this science-based information, there is a lack of information about the reality of management practices used by dairy operators for fresh cows.

The few studies available on management practices for postpartum dairy cows focus on specific aspects such as high milk production (Kellogg et al., 2001), management routines for heifers (Nyman et al., 2009), and factors that influence reproductive performance (Caraviello et al., 2006) or animal well-being (Fulwider et al., 2008). Current information about practices implemented in the management of fresh cows considering different herd sizes of commercial dairy farms is not available. Therefore, the objectives were to identify current management practices related to fresh cows in Germany via a survey of dairy managers, paying attention to factors that could influence animal health postpartum.

A survey was developed that consisted of a total of 25 questions regarding aspects of the fresh cow program including general management (6 questions), calving (8 questions), and diseases and veterinary service (11 questions). The survey form was sent by mail using 2 convenience samples in November 2006: 1) to members (n $=620$ ) of a regional German Dairy Herd Improvement Service [Landeskontrollverband Brandenburg; region 1, which was located in Brandenburg (northeastern Germany)] and 2) to the customers $(\mathrm{n}=3,000)$ of a semen sales company [Rinderzucht Schleswig Holstein; region 2, which was located in Schleswig Holstein (northern Germany)]. The survey forms were returned anonymously by mail or through the AI technicians. Data were analyzed using SPSS for Windows (Version 12.0, SPSS Inc., Munich, Germany). Means and corresponding standard deviations were computed for continuous and ordinal variables, whereas frequencies were tabulated for binary and categorical variables. Questions were analyzed by herd size, with herds categorized as small ( $<100$ cows; $\mathrm{n}=329$ ), medium (100 to 199 cows; $\mathrm{n}=63)$, or large $(\geq 200$ cows; $\mathrm{n}=37)$ based on the 
number of cows. Percentages were rounded to the nearest whole percentage point.

A total of 433 survey forms were returned resulting in a $12 \%$ response rate (region $1: 8 \%, \mathrm{n}=50$; region 2: $13 \%, \mathrm{n}=383$ ). Four survey forms were not usable and were withdrawn from analysis. On the remaining 429 survey forms most questions had been answered and were used for the final analysis. On 85 and $91 \%$ of the returned survey forms all questions were answered regarding general management and calving, respectively. The proportion of all questions answered was lower for items related to disease prevalences $(70 \%)$. Our response rate was similar to that of a mail survey on crossbreeding (Weigel and Barlass, 2003; 9.5\%), but considerably lower than that of a survey on reproductive management that was directly administered by a single interviewer (Caraviello et al., 2006; 67.3\%).

Table 1 provides a summary of responses regarding calving, examinations of fresh cows, and prevalence of disorders. A designated maternity pen was available on $90 \%$ of the responding dairy farms. In most cases (66\%) it was a box stall. However, only $22 \%$ of the responding herd managers indicated having a special group or pen for fresh cows. The majority of the responding dairy farmers recorded the type of calving (74\%) and estimated the percentage of assisted calvings at $32 \%$. This figure is in agreement with the range previously reported for multiparous (29\%) and primiparous (51\%) cows (Lombard et al., 2007). The definition of dystocia was subjective and not well defined.

Regarding the frequency of fresh cow examinations, $64 \%$ of the responding herd managers answered with "once or twice a day" and $28 \%$ with "only if needed." The frequency distribution of fresh cow examinations was different between herd sizes. Small and medium farms checked their fresh cows "only if needed" in 33 and $21 \%$, respectively, whereas only $3 \%$ of the large farms implemented this schedule.

Farm managers who had answered the item regarding the frequency of fresh cow examinations "once or twice a day" reported a higher incidence of fever compared with farm managers who had answered "only if needed" (9 vs. 6\%). In contrast, farm managers who had answered "only if needed" reported a $2 \%$ higher prevalence of clinical ketosis (8 vs. 6\%). Our data set did not permit testing a relationship between frequency of examination and estimated prevalence rates of fever and ketosis. It is plausible that a less frequent examination of fresh cows leads to under diagnosis of cows with fever and reduced appetite increasing the risk of ketosis.

Whereas the majority of the responding dairy managers $(71 \%)$ performed a fresh cow check at least once a week, only $19 \%$ also recorded the observations. Most of the dairy managers used more or less subjective criteria such as general appearance (97\%) and appetite (70\%). The importance of BCS, testing for subclinical ketosis, and measuring body temperature is well documented (Veerkamp et al., 2000; Benzaquen et al., 2007; Walsh et al., 2007). Furthermore, the diagnostic tools are easy to use and their results repeatable (Edmonson et al., 1989; Iwersen et al., 2009, Burfeind et al., 2010). Yet, only a minority of the responding dairy managers monitored their fresh cows for subclinical ketosis (3\%), fever $(34 \%)$, or BCS $(36 \%)$. Interesting differences existed between farms that did and did not use certain diagnostic criteria. On farms that checked for general appearance, the estimated prevalence of clinical ketosis was 6 percentage units higher compared with farms that did not check for general appearance (7 vs. 1\%). One explanation for this observation is that a regular examination of fresh cows identifies more cows at risk for illness even though the evaluation of general appearance is an unspecific and subjective test. Farms not monitoring body temperature in fresh cows reported lower prevalence rates of metritis (8 vs. 10\%) and fever (6 vs. 11\%) compared with farms measuring body temperature. Obviously, a fresh cow program including a regular measurement of body temperature identified more cases of metritis (i.e., fever and discharge). If body temperature is not checked several metritis cases remain undiagnosed.

Overall, postpartum disorders were recorded by $39 \%$ of the responding dairy farmers. The most frequently recorded disorders were milk fever $(62 \%)$ and cases of retained placenta (62\%). Frequencies of left displacements of abomasum, metritis, and discharge were 46, 44 , and $45 \%$, respectively. Cases of fever (29\%) and ketosis $(26 \%)$ were recorded relatively infrequently. The range of reported prevalence rates analyzed as 25 and 75 percentiles for retained placenta $(6 ; 15 \%)$, metritis $(3 ; 11 \%)$, and discharge $(5 ; 15 \%)$ was large.

Table 2 provides a summary of information regarding the reported frequency of veterinary visits and treatment of postpartum disorders. As expected, analyzing farms by different size categories showed considerable differences regarding frequency of veterinary visits. The veterinarian visited the herds "only if needed" in 80,65 , and $19 \%$ of small, medium, and large farms, respectively. Veterinary visits were reported once a day in 1, 5, and $32 \%$ of small, medium, and large farms, respectively. Overall, farms with $<100$ cows and with 100 to 199 cows were more similar than farms with $\geq 200$ cows. A similar finding was reported for colostrum management practices (Kehoe et al., 2007).

Cases of retained placenta were treated with removal of the fetal membranes (72\%), antibiotic pills (90\%), and systemic antibiotics (14\%). These intervention prefer- 
Table 1. Summary of responses by herd managers $(\mathrm{n}=429)$ to questions related to calving and fresh cow management, along with corresponding means $\pm \mathrm{SD}$ (continuous variables) or percentages (binary or categorical variables)

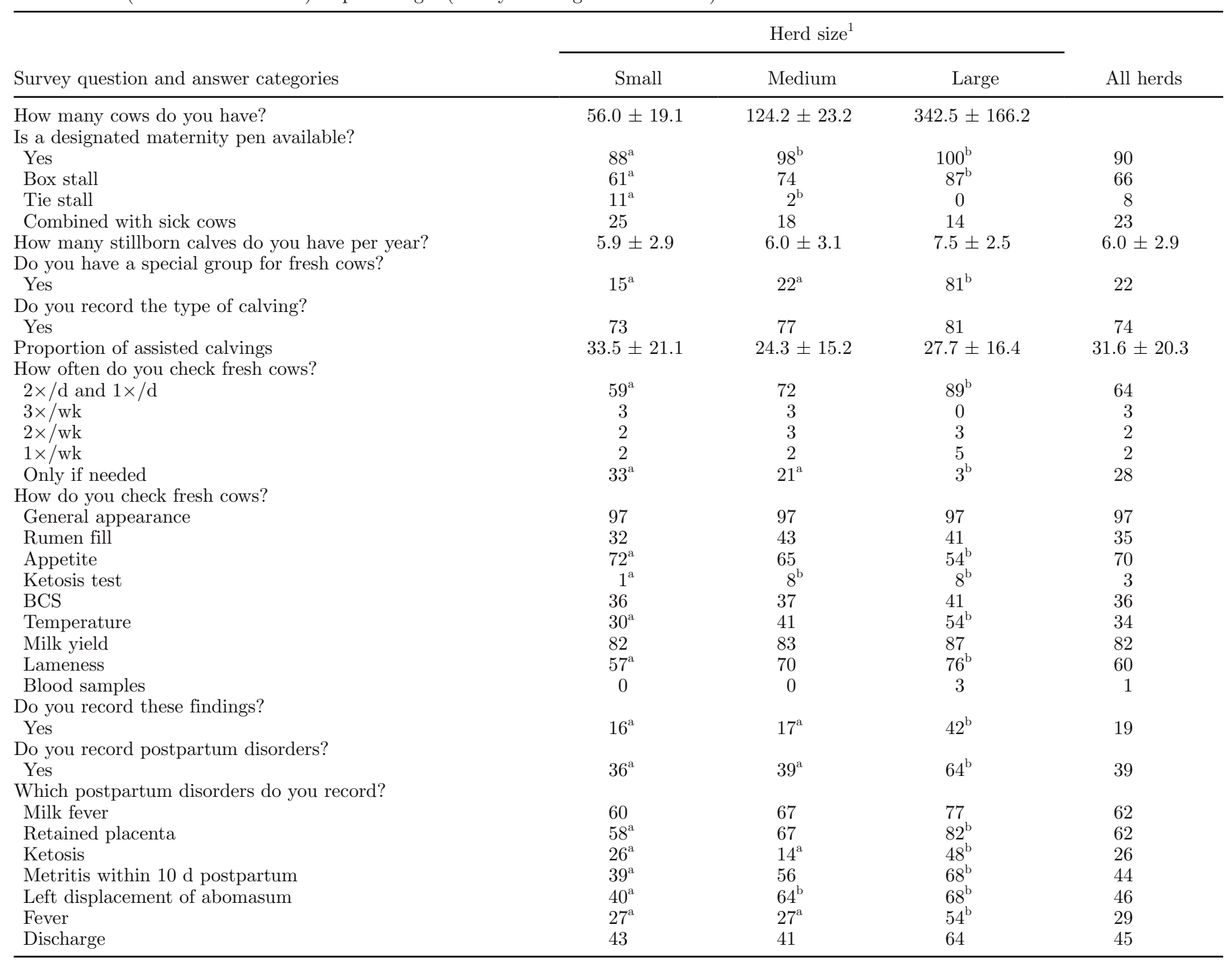

${ }^{\mathrm{a}, \mathrm{b}}$ Within a row, different superscripts indicate significant differences between the size categories $(P<0.05)$.

${ }^{1}$ Herd size: small $=<100$ cows $(\mathrm{n}=329)$; medium $=100$ to 199 cows $(\mathrm{n}=63)$; large $=\geq 200$ cows $(\mathrm{n}=37)$.

ences demonstrate a reluctance to abandon a treatment that was traditionally perceived as efficacious. Drillich et al. (2006) provided strong evidence that manual removal of the fetal membranes and administration of antibiotic drugs into the uterus for the treatment of retained placenta were not beneficial. Regarding the use of systemic antibiotic drugs, significant differences existed between small and medium versus large farms. This could be because of the higher incidence rates of fever during the first $10 \mathrm{~d}$ postpartum on large farms (Drillich et al., 2007). For cows with discharge and fever indicative of acute postpartum metritis, farm managers used a systemic antibiotic treatment more often (48\%) and intrauterine administration of pills less often (53\%) compared with cows with retained placenta.
The present study provides a summary of practices related to fresh cow management on small, medium, and large commercial dairy farms in Germany. Several challenges and opportunities were identified. Only a few herds had a designated fresh cow pen $(22 \%)$. Even though almost every farm executed some type of fresh cow examination, only a minority of farm managers documented those observations (19\%). Only one-third of farmers measured the body temperature of fresh cows (34\%) and only $3 \%$ used a ketosis test. On most farms, the veterinarian visited the herd only if needed (73\%), with significant differences between small or mediumsized farms compared with large farms (80 and 65 vs. $19 \%$ ). Most cases of retained fetal membranes were treated by manual removal $(72 \%)$ and pills (90\%). 
Table 2. Percentages of responding herd managers $(n=429)$ to questions related to veterinary service and treatment of postpartum disorders

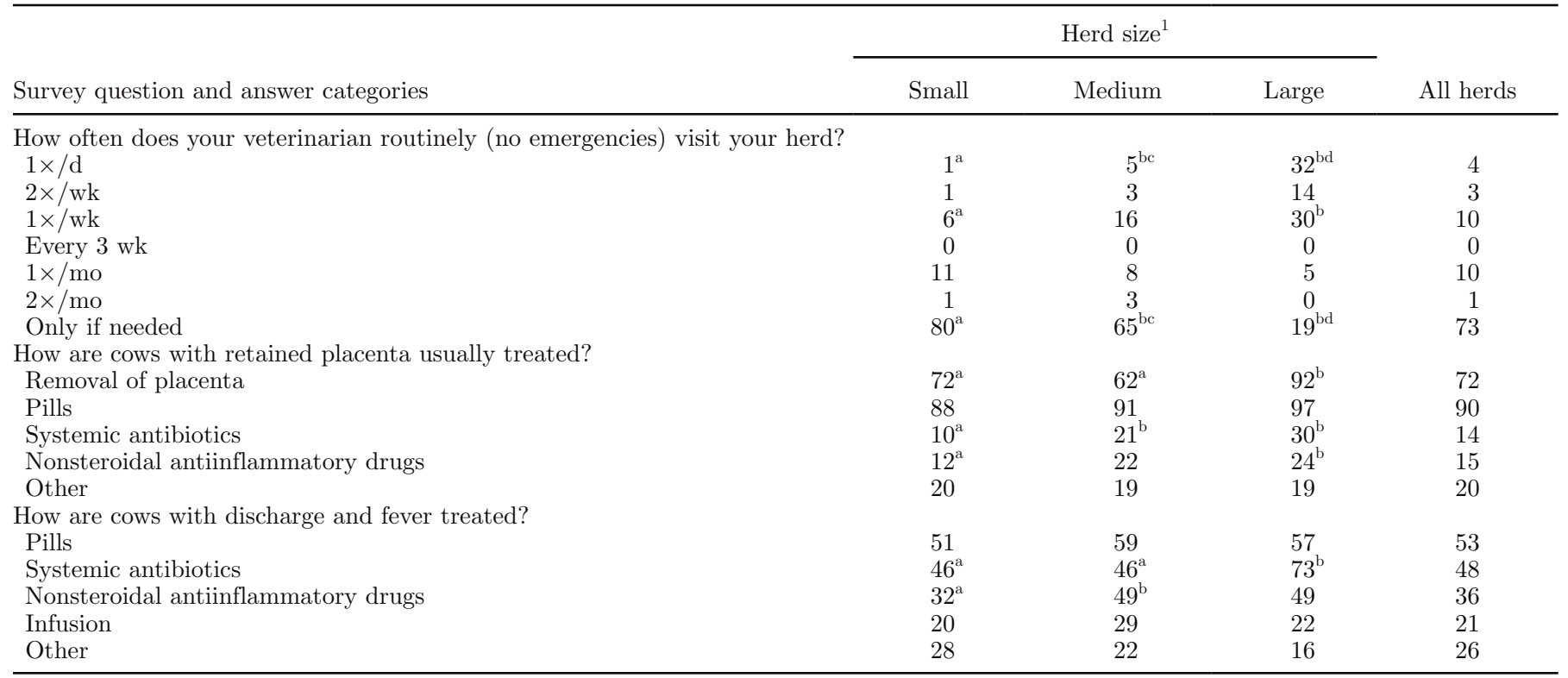

${ }^{\mathrm{a}-\mathrm{d}}$ Within a row, different superscripts indicate significant differences between the size categories $(P<0.05)$.

${ }^{1}$ Herd size: small $=<100$ cows $(\mathrm{n}=329)$; medium $=100$ to 199 cows $(\mathrm{n}=63) ;$ large $=\geq 200$ cows $(\mathrm{n}=37)$.

\section{ACKNOWLEDGMENTS}

We thank the Landeskontrollverband Brandenburg (Waldsieversdorf, Germany) and the Rinderzucht Schleswig Holstein (Neumuenster, Germany) for their valuable support in conducting this survey. This project was funded by Pfizer Animal Health, Veterinary Medicine Research and Development (United Kingdom) and by Tiergyn Berlin e.V. We thank Christian Fidelak (Clinic for Animal Reproduction, Berlin, Germany) for technical assistance.

\section{REFERENCES}

Azawi, O. I. 2008. Postpartum uterine infection in cattle. Anim. Reprod. Sci. 105:187-208.

Benzaquen, M. E., C. A. Risco, L. F. Archbald, P. Melendez, M.J. Thatcher, and W. W. Thatcher. 2007. Rectal temperature, calving-related factors, and the incidence of puerperal metritis in postpartum dairy cows. J. Dairy Sci. 90:2804-2814.

Burfeind, O., M. A. G. von Keyserlingk, D. M. Veira, D. M. Weary, and W. Heuwieser. 2010. Repeatability of rectal temperature in dairy cows. J. Dairy Sci. 93:624-627.

Caraviello, D. Z., K. A. Weigel, P. M. Fricke, M. C. Wiltbank, M. J. Florent, N. B. Cook, K. V. Nordlund, N. R. Zwald, and C. L. Rawson. 2006. Survey of management practices on reproductive performance of dairy cattle on large US commercial farms. J. Dairy Sci. 89:4723-4735.

Drillich, M., N. Klever, and W. Heuwieser. 2007. Comparison of two management strategies for retained fetal membranes on small dairy farms in Germany. J. Dairy Sci. 90:4275-4281.

Drillich, M., M. Mahlstedt, U. Reichert, B. A. Tenhagen, and W. Heuwieser. 2006. Strategies to improve the therapy of retained fetal membranes in dairy cows. J. Dairy Sci. 89:627-635.
Edmonson, A. J., I. J. Lean, L. D. Weaver, T. Farver, and G. Webster. 1989. A body condition scoring chart for Holstein dairy cows. J. Dairy Sci. 72:68-78.

Fulwider, W. K., T. Grandin, B. E. Rollin, T. E. Engle, N. L. Dalsted, and W. D. Lamm. 2008. Survey of dairy management practices on one hundred thirteen north central and northeastern United States dairies. J. Dairy Sci. 91:1686-1692.

Iwersen, M., U. Falkenberg, R. Voigtsberger, D. Forderung, and W. Heuwieser. 2009. Evaluation of an electronic cowside test to detect subclinical ketosis in dairy cows. J. Dairy Sci. 92:2618-2624.

Kehoe, S. I., B. M. Jayarao, and A. J. Heinrichs. 2007. A survey of bovine colostrum composition and colostrum management practices on Pennsylvania dairy farms. J. Dairy Sci. 90:4108-4116.

Kellogg, D. W., J. A. Pennington, Z. B. Johnson, and R. Panivivat. 2001. Survey of management practices used for the highest producing DHI herds in the United States. J. Dairy Sci. 84(E. Suppl.):E120-E127.

LeBlanc, S. J., K. D. Lissemore, D. F. Kelton, T. F. Duffield, and K. E. Leslie. 2006. Major advances in disease prevention in dairy cattle. J. Dairy Sci. 89:1267-1279.

Lombard, J. E., F. B. Garry, S. M. Tomlinson, and L. P. Garber. 2007. Impacts of dystocia on health and survival on dairy calves. J. Dairy Sci. 90:1751-1760.

Nyman, A. K., U. Emanuelson, A. H. Gustafsson, and K. PerssonWaller. 2009. Management practices associated with udder health of first-parity dairy cows in early lactation. Prev. Vet. Med. $88: 138-149$.

Veerkamp, R. F., J. K. Oldenbroek, H. J. Van Der Gaast, and J. H. J. Van Der Werf. 2000. Genetic correlation between days until start of luteal activity and milk yield, energy balance, and live weights. J. Dairy Sci. 83:577-583.

Walsh, R. B., J. S. Walton, D. F. Kelton, S. J. LeBlanc, K. E. Leslie, and T. F. Duffield. 2007. The effect of subclinical ketosis in early lactation on reproductive performance of postpartum dairy cows. J. Dairy Sci. 90:2788-2796.

Weigel, K. A., and K. A. Barlass. 2003. Results of a producer survey regarding crossbreeding on US dairy farms. J. Dairy Sci. 86:41484154 